\title{
Discovery of Nitroheterocycles Active against African Trypanosomes. In Vitro Screening and Preliminary SAR Studies
}

Vicente J. Arán ${ }^{\mathrm{a}}$, Marcel Kaiser ${ }^{\mathrm{b}, \mathrm{c}}$, and Christophe Dardonville $\mathrm{a}^{\mathrm{a}^{*}}$

a Instituto de Química Médica, CSIC, Juan de la Cierva 3, E-28006 Madrid, Spain.

b Swiss Tropical and Public Health Institute, Socinstrasse, 57, CH-4002 Basel, Switzerland.

${ }^{\mathrm{c}}$ University of Basel, Basel, Switzerland.

* Corresponding author.

Tel.: +34 912587490

Fax.: +34 915644853

e-mail: dardonville@iqm.csic.es 


\begin{abstract}
A selection of 76 nitroheterocycles and related compounds from our in-house compound library was screened in vitro against the parasite Trypanosoma brucei rhodesiense, causative agent of human African trypanosomiasis (HAT). The unspecific cytotoxicity of the compounds was also evaluated against rat myoblast L6-cells to measure the selectivity of the compounds towards the parasite. This screening revealed some preliminary structure-activity relationships (SAR) among the series, and six hit compounds showing interesting activity $\left(\mathrm{IC}_{50} \leq 10 \mu \mathrm{M}\right)$ and fair selectivity $(\mathrm{SI}>17)$. The 7-nitroquinoxalin-2-one and 5-nitroindazole scaffold derivatives $\mathbf{5 8}$ and $\mathbf{3 5}$, respectively, are particularly interesting because of their established oral bioavailability in mice. These hits represent interesting starting points for a medicinal project aimed at identifying the SAR behind this class of compounds.
\end{abstract}

Keywords: chemotherapy, Trypanosoma brucei, sleeping sickness, nitroheterocycle, quinoxalinone, indazole, indazolone, indole, cinnoline

\begin{abstract}
Abbreviations
CNS, central nervous system; DNDi, Drugs for Neglected Diseases initiative; HAT, human African trypanosomiasis; $\mathrm{IC}_{50}, 50 \%$ inhibitory concentration; $\mathrm{MEM}$, minimum essential medium; NECT, nifurtimox-eflornithine combination therapy; NTD, neglected tropical disease; SAR, structure-activity relationships; SI, selectivity index; WHO, World Health Organization.
\end{abstract}


Human African trypanosomiasis (HAT), also known as sleeping sickness, is a neglected tropical disease (NTD) endemic in sub-Saharan Africa. The causative agents are the protozoan parasites Trypanosoma brucei rhodesiense and $T$. $b$. gambiense which provoke acute and chronic forms of the disease, respectively. The parasites are transmitted by the bite of infected tsetse flies. In absence of treatment, the parasites present in the blood and lymph during early stage HAT invade the central nervous system (CNS) provoking the fatal meningoencephalitic (late) stage of the disease. ${ }^{1,2}$

The NTD status of sleeping sickness is highlighted by the fact that 3 out of the 4 drugs approved for its treatment (i.e., pentamidine, melarsoprol, suramin) were discovered more that 60 years ago. The other drug, eflornithine, was approved in 1990 for the treatment of late-stage $T . \quad b$. gambiense infection. Other authors have reviewed the shortcomings of those drugs especially regarding toxicity, lack of oral bioavailability or lack of efficiency. ${ }^{3}$ Apart from the recent inclusion of the nifurtimox-eflornithine combination therapy (NECT) in the WHO list of essential medicines, no new drugs have been registered for HAT in the last 20 years (http://www.who.int/selection_medicines/committees/expert/17/application/nifurtimox/ en/index.html).

In the last years, the public-private partnership research efforts of the Drugs for Neglected Diseases initiative (DNDi) have been rewarded by the discovery of two potential drug candidates (the nitroimidazole fexinidazole and the oxaborole SCYX7158, Fig. 1) which have entered phase I clinical development for both acute and chronic sleeping sickness. ${ }^{4,5}$ These were discovered by screening chemical libraries of compounds against African trypanosomes. The fact that a nitroimidazole derivative, fexinidazole, is one the most promising new drug candidate for the oral treatment of 
both stages of HAT, despite the inherent caution usually associated with nitroheterocycles as drug candidates, led us to consider our library of nitroheterocycles as a possible source of new hits against African trypanosomes. In fact, some of our nitroheterocyclic compounds and related compounds have already shown interesting in vivo and/or in vitro activity against the protozoa $T$. cruzi, etiological agent of American trypanosomiasis (Chagas' disease), ${ }^{6-13}$ Trichomonas vaginalis ${ }^{13-18}$ and Leishmania spp.; ${ }^{10}$ other compounds were effective inhibitors of biocrystallization of ferriprotoporphyrin IX (heme) to hemozoin and thus, potential antimalarial agents. ${ }^{19,20}$ Besides, it should be kept in mind that the nitroheterocycles benznidazole and nifurtimox (Fig. 1) are currently the only drugs available for the treatment of American trypanosomiasis which emphasizes the importance of this class of chemical structures as antiprotozoal agents.

We report here the in vitro screening against $T . b$. rhodesiense (strain STIB900) of a selection of 76 nitro-derivatives of nitrogenated heterocycles (e.g., nitrocinnolines, nitroindoles, nitroindazoles and nitroquinoxalinones) and related compounds ${ }^{13}, 19,21-30,31$ using the Alamar blue growth inhibition assay. ${ }^{32}$ Their cytotoxicity against mammalian L6-cells was also determined in vitro. This allowed the calculation of a selectivity index defined as: $\mathrm{SI}=\mathrm{IC}_{50}(\mathrm{~L} 6-$ cells $) / \mathrm{IC}_{50}(T . b . r$.$) . This screening revealed some SAR$ among the series and a few hit compounds showing interesting activity and fair selectivity. These hits could be used as starting points for a medicinal chemistry optimization program. 
<smiles>CSc1ccc(OCc2ncc([N+](=O)[O-])n2C)cc1</smiles>

Fexinidazole<smiles>O=C(Cn1ccnc1[N+](=O)[O-])NCc1ccccc1</smiles><smiles>CC1(C)OB(O)c2cc(NC(=O)c3ccc(F)cc3C(F)(F)F)ccc21</smiles>

SCYX-7158<smiles>C[C@@H]1CC(=O)CCN1/N=C/c1ccc([N+](=O)[O-])o1</smiles>

Nifurtimox

Figure 1. Drugs currently in clinical development for the oral treatment of both stages of sleeping sickness (top) and drug used clinically against $T$. cruzi infections (bottom)

Compounds from the hydrazide series (Table 1) had $\mathrm{IC}_{50}$ values against $T$. brucei in the range 5.5 to $>400 \mu \mathrm{M}$. Seven compounds showed $\mathrm{IC}_{50}<50 \mu \mathrm{M}(\mathbf{3}, \mathbf{1 1}, \mathbf{1 6}, \mathbf{1 7}-\mathbf{2 0})$ but only three of those $(\mathbf{3}, \mathbf{1 1}$, and $\mathbf{2 0})$ were selective for the parasite with SI of 8.3, 13.7, and 13 , respectively. Of note is the effect of replacing the 6-halogen atom $(\mathrm{Cl}, \mathrm{F})$ by an ethoxy group in 20; this reduced significantly the cytotoxicity (13- to 57-fold) with only a two-fold decrease in antitrypanosomal activity with respect to $\mathbf{1 8}$ and $\mathbf{1 9 .}$

[insert Table 1 here]

5-Nitroindazolols derivatives with free $\mathrm{OH}$ group (Table 2) were only weakly active against $T$. b. rhodesiense $\left(\mathrm{IC}_{50}>63 \mu \mathrm{M}\right)$. The best results, with $\mathrm{IC}_{50}$ values in the range 5-12 $\mu \mathrm{M}$ and $\mathrm{SI}=5.3-11.6$, were obtained with compounds bearing a basic amino side 
chain such as 5-piperidinopentyl (34), 2-(2-piperidinoethoxy)ethyl (35), 2(dimethylamino)ethyl (38), and 3-(dimethylamino)propyl.

[insert Table 2 here]

Among indazolinone derivatives (Table 3), only 4 compounds (i.e., those holding a benzyl group on the $\mathrm{N} 2$ nitrogen) had $\mathrm{IC}_{50}<50 \mu \mathrm{M}(\mathbf{5 2 - 5 5 )}$ although with low selectivity (SI $=0.8-5.3)$. Compound 52 with N1-methyl-N2-benzyl substituents was the most active and selective of this series with $\mathrm{IC}_{50}=8.2 \mu \mathrm{M}$ and $\mathrm{SI}=5.3$. It is worth noting that increasing the size of the N1-substituent decreased significantly the activity of the compound in the order: methyl $>$ propyl $>$ butyl $\approx$ benzyl (i.e., 52-55). The regioisomer with N2-methyl-N1-benzyl substituents (51) was 20-times less active than 52.

[insert Table 3 here]

The quinoxalin-2-one scaffold gave the best antitrypanosomal compounds with 6 molecules $(\mathbf{5 7}, \mathbf{5 8}, \mathbf{5 9}, \mathbf{6 0}, \mathbf{6 2}, \mathbf{6 5})$ having $\mathrm{IC}_{50}$ values $<15 \mu \mathrm{M}$ and $\mathrm{SI}$ values in the range 3.6-39.7 (Table 4). The N1,N4-dimethyl compound $\mathbf{5 8}$ and the fused pyrrolidine derivative 65 were the most active compounds of this screening $\left(\mathrm{IC}_{50}=3.6\right.$ and $2.7 \mu \mathrm{M}$, respectively). Methylation of the N1-nitrogen generally increased the activity by approximately 2-fold (compare 57 vs 58, 61 vs 62, and 69 vs 70) except for compounds 66 and 67 where the opposite effect was observed. This substitution was generally accompagnied by an increase in cytotoxicity. Five and six methylene chloroalkyl chains 
at $\mathrm{N} 1$ also gave low $\mathrm{IC}_{50}$ values (7.5 and $6.9 \mu \mathrm{M}$ for $\mathbf{5 9}$ and $\mathbf{6 0}$, respectively) and fair selectivities (13.1 and 6.4, respectively). On the contrary, fused bulky rings such as piperidine $(66-68)$, isoquinoline $(69,70)$, or benzo $[d]$ azepine $(63,64)$ gave mostly cytotoxic compounds (i.e., $\mathrm{SI}<1$ ).

The bisnitroindazole derivatives were poorly active against $T$. brucei (Table 5 ). The sole compound with interesting activity was the urea $\mathbf{7 6}$ which was one of the best hits of this study with $\mathrm{IC}_{50}=7.1 \mu \mathrm{M}$ and $\mathrm{SI}>23.6$.

[insert Tables 4 and 5 here]

The discovery of fexinidazole as a potential clinical candidate for the oral treatment of both stages of sleeping sickness has led, in the last years, to a renewed interest in nitroheterocyclic compounds as possible antitrypanosomal agents. In this study, we have taken advantage of our compound library, historically rich in nitroheterocyclic compounds, and selected 76 molecules from different groups to be tested against $T$. brucei (i.e., nitrobenzohydrazide, indazolol, indazolinone, quinoxalin-2-one, bisindazolols, etc.). From the data collected in this study, the SAR for anti-T. brucei activity is limited even though a few significant trends could be found for the quinoxalin-2-one and indazole series. In particular, the bulk around the N1-position of the molecule seems to be rather restricted. Thus, a small methyl substituent is allowed $(\mathbf{5 7}, \mathbf{5 8})$ as well as fused pyrrolidine ring $(\mathbf{6 5})$. Long alkylic chains are also favored $(\mathbf{5 9}$, 60) probably because they are quite flexible and can stay away from the steric restricted area around N1. On the contrary, bulkier fused substituents at N1 are detrimental to the activity. Important SAR results are depicted in Figure 2. 

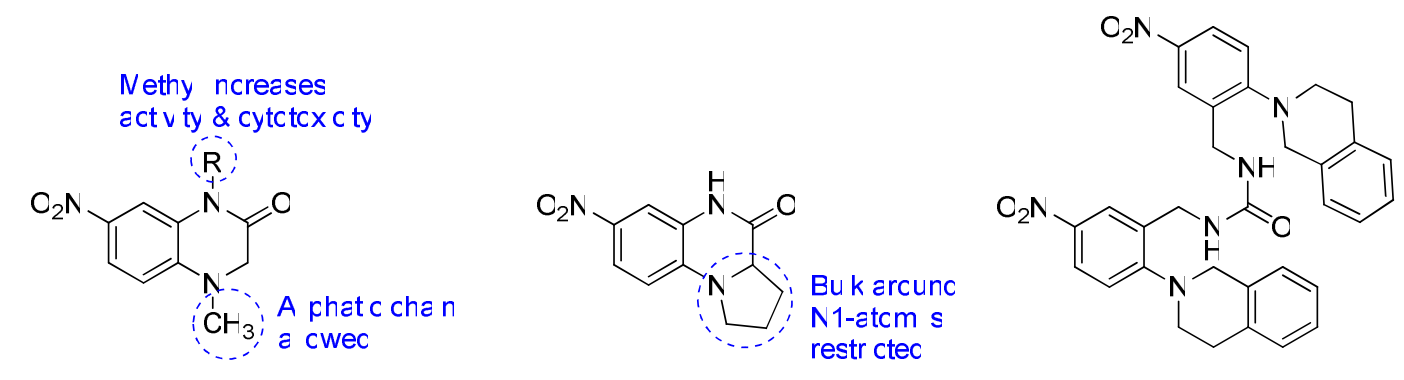

$57 \mathrm{R}=\mathrm{H} \quad \mathrm{C}_{50}=1 \mathrm{C} 6 \mu \mathrm{N}(\mathrm{S}=3 \subseteq 7)$
$58 \mathrm{R}=\mathrm{CH}_{3} \quad \mathrm{C}_{50}=36 \mu \mathrm{N}(\mathrm{S}=216)$

$65 \mathrm{C}_{50}=27 \mu \mathrm{N}(\mathrm{S}=174)$
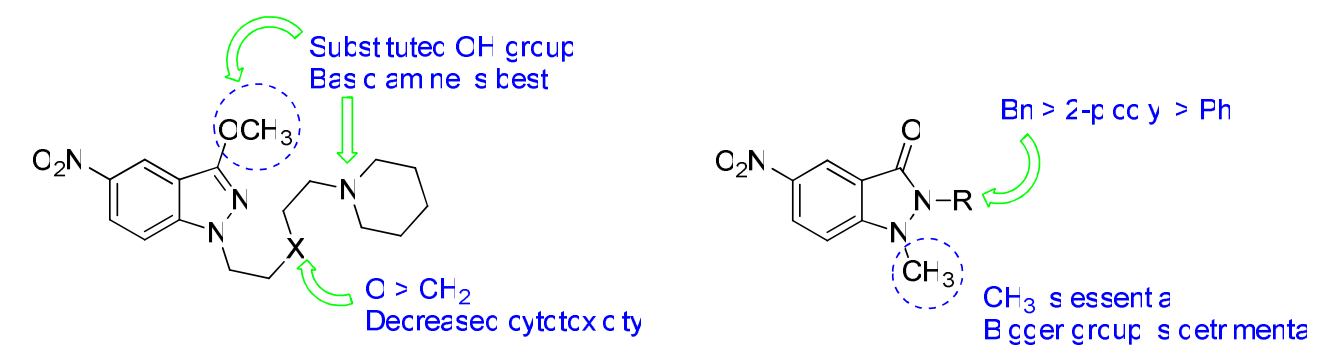

$34 X=\mathrm{CH}_{2} \quad \mathrm{C}_{50}=5 \Sigma \mu \mathrm{N}(\mathrm{S}=112)$

$35 \mathrm{X}=\mathrm{C} \quad \mathrm{C}_{50}=11 \varepsilon \mu \mathrm{N}(\mathrm{S}=116)$

$52 \mathrm{R}=\mathrm{Bn} \quad \mathrm{C}_{50}=\varepsilon 2 \mu \mathrm{N}(\mathrm{S}=\Xi \Xi)$

Figure 2. Summary of the hit compounds active against $T$. $b$. rhodesiense and selective over L6-cells. Important SAR features for anti-T. brucei activity are highlighted.

Interestingly, several of the hits identified in this screening are also lead compounds against $T$. cruzi or $T$. vaginalis. On the one hand, $\mathbf{5 8}$ showed in vitro activity against epimastigotes and intracellular amastigotes of T. cruzi, as well as in vivo suppressive activity by oral route in a murine model of acute $T$. cruzi infection. ${ }^{11}$ In the same study, Vega et al. showed that $\mathbf{6 5}$ was active but more cytotoxic that $\mathbf{5 8}$. Hence, despite the moderate selectivity for T. brucei over rat L6-cells (21.6-fold) found in our screening, 58 seems to have adequate physicochemical properties for oral bioavailability and may well be an interesting lead compound worth investigating as anti-T. brucei agent. On the other hand, $\mathbf{3 4}$ was reported to be very active against $T$. vaginalis whilst its activity against $T$. cruzi was moderate. ${ }^{13}$ However, the 2-(2-piperidinoethoxy)ethyl analogue 35 showed similar in vitro anti-T. cruzi efficacy with reduced cytotoxicity compared to 
$\mathbf{3 4} ;{ }^{10}$ this finding is confirmed here as $\mathbf{3 4}$ has 2-fold higher cytotoxicity against L6-cells than 35. Besides, Boiani et al. have shown that $\mathbf{3 5}$ was active in vivo by oral administration in a murine model of acute Chagas' infection indicating adequate bioavailability for this compound. ${ }^{10}$ These data indicate that $\mathbf{3 5}$ may also be a good trypanocidal lead for HAT.

At this stage, the target and mode of action of these compounds against African trypanosomes remain unknown. In T. cruzi, the action of this kind of molecules seems to be associated with the production of reduced species of the $5-\mathrm{NO}_{2}$ moiety similarly to what happens with benznidazole ${ }^{8,9}$ or nifurtimox. ${ }^{33}$ Thus, the antitrypanosomal action of these compounds, like fexinidazole, could possibly involve bioreductive activation by parasite type I nitroreductase leading to reactive intermediates that would provoke cellular damage. ${ }^{5,34,35}$ Hall \& Wilkinson have shown recently that the bioactivation of benznidazole by $T$. brucei type I nitroreductase generates the reactive dialdehyde glioxal which in turn leads to glyoxal-guanosine adducts. The authors suggest that the trypanocidal activity of benznidazole is the result of DNA damage by these metabolites. ${ }^{36}$ However, the nitroheterocycles reported here cannot be metabolized to glioxal by reductive activation. This means that other mechanism of action (or metabolites) may be involved. This hypothesis will need experimental confirmation.

Altogether, the results of our in vitro screening against $T$. brucei take their importance in the light of the previous data of antiprotozoal activity reported for those compounds and related nitroimidazoles. For instance, the lead compound fexinidazole, which is currently in clinical trials for $\mathrm{HAT}$, has $\mathrm{IC}_{50}$ values in the range $1.71-2.93 \mu \mathrm{M}$ against $T$. b. rhodesiense STIB900 in the same assay. ${ }^{5}$ Even though fexinidazole selectivity (SI > 322 ) is higher than that of our compounds, some of the hits presented here could be good starting points for an optimization program directed towards the discovery of new 
antitrypanosomal agents for the treatment of sleeping sickness. This is the case, in particular, of the 7-nitroquinoxalin-2-one $\mathbf{5 8}$ and the 5-nitroindazole $\mathbf{3 5}$ that have demonstrated low micromolar activity and in vivo bioavailability in mice .

\section{Acknowledgements}

This work was supported by grants from the Spanish Ministerio de Ciencia e Innovación (Grants SAF2006-04698 and SAF2009-10399). We thank M. Cal, S. Sax and C. Stalder (Swiss TPH) for parasite assay results.

\section{References}

1. $\quad$ Brun, R.; Blum, J.; Chappuis, F.; Burri, C. Lancet 2010, 375, 148.

2. WHO. World Health Organization: Geneva, 2010.

3. Burri, C. Parasitology 2010, 137, 1987.

4. Jacobs, R. T.; Nare, B.; Wring, S. A.; Orr, M. D.; Chen, D.; Sligar, J. M.; Jenks, M. X.; Noe, R. A.; Bowling, T. S.; Mercer, L. T.; Rewerts, C.; Gaukel, E.; Owens, J.; Parham, R.; Randolph, R.; Beaudet, B.; Bacchi, C. J.; Yarlett, N.; Plattner, J. J.; Freund, Y.; Ding, C.; Akama, T.; Zhang, Y. K.; Brun, R.; Kaiser, M.; Scandale, I.; Don, R. PLoS Negl. Trop. Dis. 2011, 5, e1151.

5. Torreele, E.; Bourdin Trunz, B.; Tweats, D.; Kaiser, M.; Brun, R.; Mazué, G.; Bray, M. A.; Pécoul, B. PLoS Negl. Trop. Dis. 2010, 4, e923.

6. Castillo-Garit, J. A.; Vega, M. C.; Rolón, M.; Marrero-Ponce, Y.; GómezBarrio, A.; Escario, J. A.; Bello, A. A.; Montero, A.; Torrens, F.; Pérez-Giménez, F.; Arán, V. J.; Abad, C. Eur. J. Med. Chem. 2011, 46, 3324. 
7. Aguilera-Venegas, B.; Olea-Azar, C.; Norambuena, E.; Arán, V. J.; Mendizábal, F.; Lapier, M.; Maya, J. D.; Kemmerling, U.; López-Muñoz, R. Spectrochim. Acta Part A: Mol. Biomol. Spectr. 2011, 78, 1004.

8. Rodríguez, J.; Gerpe, A.; Aguirre, G.; Kemmerling, U.; Piro, O. E.; Arán, V. J.; Maya, J. D.; Olea-Azar, C.; González, M.; Cerecetto, H. Eur. J. Med. Chem. 2009, 44, 1545 .

9. Rodríguez, J.; Arán, V. J.; Boiani, L.; Olea-Azar, C.; Lavaggi, M. L.; González, M.; Cerecetto, H.; Maya, J. D.; Carrasco-Pozo, C.; Speisky Cosoy, H. Bioorg. Med. Chem. 2009, 17, 8186.

10. Boiani, L.; Gerpe, A.; Arán, V. J.; Torres de Ortiz, S.; Serna, E.; Vera de Bilbao, N.; Sanabria, L.; Yaluff, G.; Nakayama, H.; Rojas de Arias, A.; Maya, J. D.; Morello, J. A.; Cerecetto, H.; González, M. Eur. J. Med. Chem. 2009, 44, 1034.

11. Vega, M. C.; Montero-Torres, A.; Marrero-Ponce, Y.; Rolón, M.; GómezBarrio, A.; Escario, J. A.; Arán, V. J.; Nogal, J. J.; Meneses-Marcel, A.; Torrens, F. Bioorg. Med. Chem. Lett. 2006, 16, 1898.

12. Montero-Torres, A.; Vega, M. C.; Marrero-Ponce, Y.; Rolón, M.; GómezBarrio, A.; Escario, J. A.; Arán, V. J.; Martínez-Fernández, A. R.; Meneses-Marcel, A. Bioorg. Med. Chem. 2005, 13, 6264.

13. Arán, V. J.; Ochoa, C.; Boiani, L.; Buccino, P.; Cerecetto, H.; Gerpe, A.; González, M.; Montero, D.; Nogal, J. J.; Gómez-Barrio, A.; Azqueta, A.; López De Ceráin, A.; Piro, O. E.; Castellano, E. E. Bioorg. Med. Chem. 2005, 13, 3197.

14. Marrero-Ponce, Y.; Meneses-Marcel, A.; Rivera-Borroto, O. M.; GarcíaDomenech, R.; Julián-Ortiz, J. V.; Montero, A.; Escario, J. A.; Gómez Barrio, A.; Montero Pereira, D.; Nogal, J. J.; Grau, R.; Torrens, F.; Vogel, C.; Arán, V. J. J. Comput.-Aided Mol. Des. 2008, 22, 523. 
15. Marrero-Ponce, Y.; Meneses-Marcel, A.; Castillo-Garit, J. A.; MachadoTugores, Y.; Escario, J. A.; Barrio, A. G.; Pereira, D. M.; Nogal-Ruiz, J. J.; Arán, V. J.; Martínez-Fernández, A. R.; Torrens, F.; Rotondo, R.; Ibarra-Velarde, F.; Alvarado, Y. J. Bioorg. Med. Chem. 2006, 14, 6502.

16. Meneses-Marcel, A.; Marrero-Ponce, Y.; Machado-Tugores, Y.; MonteroTorres, A.; Montero Pereira, D.; Escario, J. A.; Nogal-Ruiz, J. J.; Ochoa, C.; Arán, V. J.; Martínez-Fernández, A. R.; García Sánchez, R. N. Bioorg. Med. Chem. Lett. 2005, 15,3838 .

17. Marrero-Ponce, Y.; Machado-Tugores, Y.; Montero Pereira, D.; Escario, J. A.; Gómez Barrio, A.; Nogal-Ruiz, J. J.; Ochoa, C.; Arán, V. J.; Martínez-Fernández, A. R.; García Sánchez, R. N.; Montero-Torres, A.; Torrens, F.; Meneses-Marcel, A. Curr. Drug Discov. Tech. 2005, 2, 245.

18. Rivera-Borroto, O. M.; Marrero-Ponce, Y.; Meneses-Marcel, A.; Escario, J. A.; Gómez Barrio, A.; Arán, V. J.; Martins Alho, M. A.; Montero Pereira, D.; Nogal, J. J.; Torrens, F.; Ibarra-Velarde, F.; Vera Montenegro, Y.; Huesca-Guillén, A.; Rivera, N.; Vogel, C. QSAR Comb. Sci. 2009, 28, 9.

19. Martins Alho, M. A.; García-Sánchez, R. N.; Nogal-Ruiz, J. J.; Escario, J. A.; Gómez-Barrio, A.; Martínez-Fernández, A. R.; Arán, V. J. ChemMedChem 2009, 4, 78. 20. Montero-Torres, A.; García-Sanchez, R. N.; Marrero-Ponce, Y.; MachadoTugores, Y.; Nogal-Ruiz, J. J.; Martínez-Fernández, A. R.; Arán, V. J.; Ochoa, C.; Meneses-Marcel, A.; Torrens, F. Eur. J. Med. Chem. 2006, 41, 483.

21. Reino, J. L.; Saiz-Urra, L.; Hernández-Galán, R.; Arán, V. J.; Hitchcock, P. B.; Hanson, J. R.; Gonzalez, M. P.; Collado, I. G. J. Agr. Food Chem. 2007, 55, 5171.

22. Chicharro, R.; De Castro, S.; Reino, J. L.; Arán, V. J. Eur. J. Org. Chem. 2003, 2314. 
23. De Castro, S.; Chicharro, R.; Arán, V. J. J. Chem. Soc., Perkin Trans. 12002 , 790.

24. Arán, V. J.; Asensio, J. L.; Molina, J.; Muñoz, P.; Ruiz, J. R.; Stud, M. J. Chem. Soc. Perkin Trans. 1 1997, 2229.

25. Arán, V. J.; Flores, M.; Muñoz, P.; Páez, J. A.; Sánchez-Verdú, P.; Stud, M. Liebigs Ann. 1996, 683.

26. Arán, V. J.; Flores, M.; Muñoz, P.; Ruiz, J. R.; Sánchez-Verdú, P.; Stud, M. Liebigs Ann. 1995, 817.

27. Ruiz, J. R.; Arán, V. J.; Asensio, J. L.; Flores, M.; Stud, M. Liebigs Ann. 1994, 679.

28. Arán, V. J.; Asensio, J. L.; Ruiz, J. R.; Stud, M. J. Chem. Soc., Perkin Trans. 1 $1993,1119$.

29. Arán, V.; Asensio, J. L.; Ruiz, J. R.; Stud, M. J. Chem. Res. (M) 1993, 1322.

30. De Castro, S. Degree Thesis, Universidad Autónoma de Madrid, September 2000.

31. The synthesis of $\mathbf{3 1}$, and $\mathbf{5 3 - 5 6}$ will be published elsewhere.

32. Räz, B.; Iten, M.; Grether-Bühler, Y.; Kaminsky, R.; Brun, R. Acta Trop. 1997, 68,139

33. Wilkinson, S. R.; Taylor, M. C.; Horn, D.; Kelly, J. M.; Cheeseman, I. Proc. Natl Acad. Sci. USA 2008, 105, 5022.

34. Sokolova, A. Y.; Wyllie, S.; Patterson, S.; Oza, S. L.; Read, K. D.; Fairlamb, A. H. Antimicrob. Agents Chemother. 2010, 54, 2893.

35. Hall, B. S.; Bot, C.; Wilkinson, S. R. J. Biol. Chem. 2011, 286, 13088.

36. Hall, B. S.; Wilkinson, S. R. Antimicrob. Agents Chemother. 2012, 56, 115. 


\section{Graphical Abstract}<smiles>[R]N1CC(=O)N([R])c2ccc([N+](=O)[O-])cc21</smiles><smiles>O=C1Nc2cc([N+](=O)[O-])ccc2N2CCCC12</smiles>

$58 \mathrm{R}^{1}=\mathrm{R}^{2}=\mathrm{CH}_{3}$

$65 \mathrm{IC}_{5 \mathrm{C}}=27 \mu \mathrm{M}(\mathrm{SI}=174)$

$I C_{5 C}=36 \mu \mathrm{M}(S I=216)$<smiles>[R]n1c(=O)c2cc([N+](=O)[O-])ccc2n1[R]</smiles><smiles>[R]CCCn1nc(O[R])c2cc([N+](=O)[O-])ccc21</smiles>

$52 \mathrm{R}^{1}=\mathrm{Bn} \mathrm{R}^{2}=\mathrm{CH}_{3}$

$35 \mathrm{X}=\mathrm{O}$

$\mathrm{IC}_{5 \mathrm{C}}=82 \mu \mathrm{M}(\mathrm{SI}=53)$

$\mathrm{IC}_{5 \mathrm{C}}=11 \& \mu \mathrm{M}(\mathrm{SI}=116)$ 
Table 1. In Vitro Activity of Hydrazides (1-20) and Related Compounds (21-22) against $T$. brucei rhodesiense.

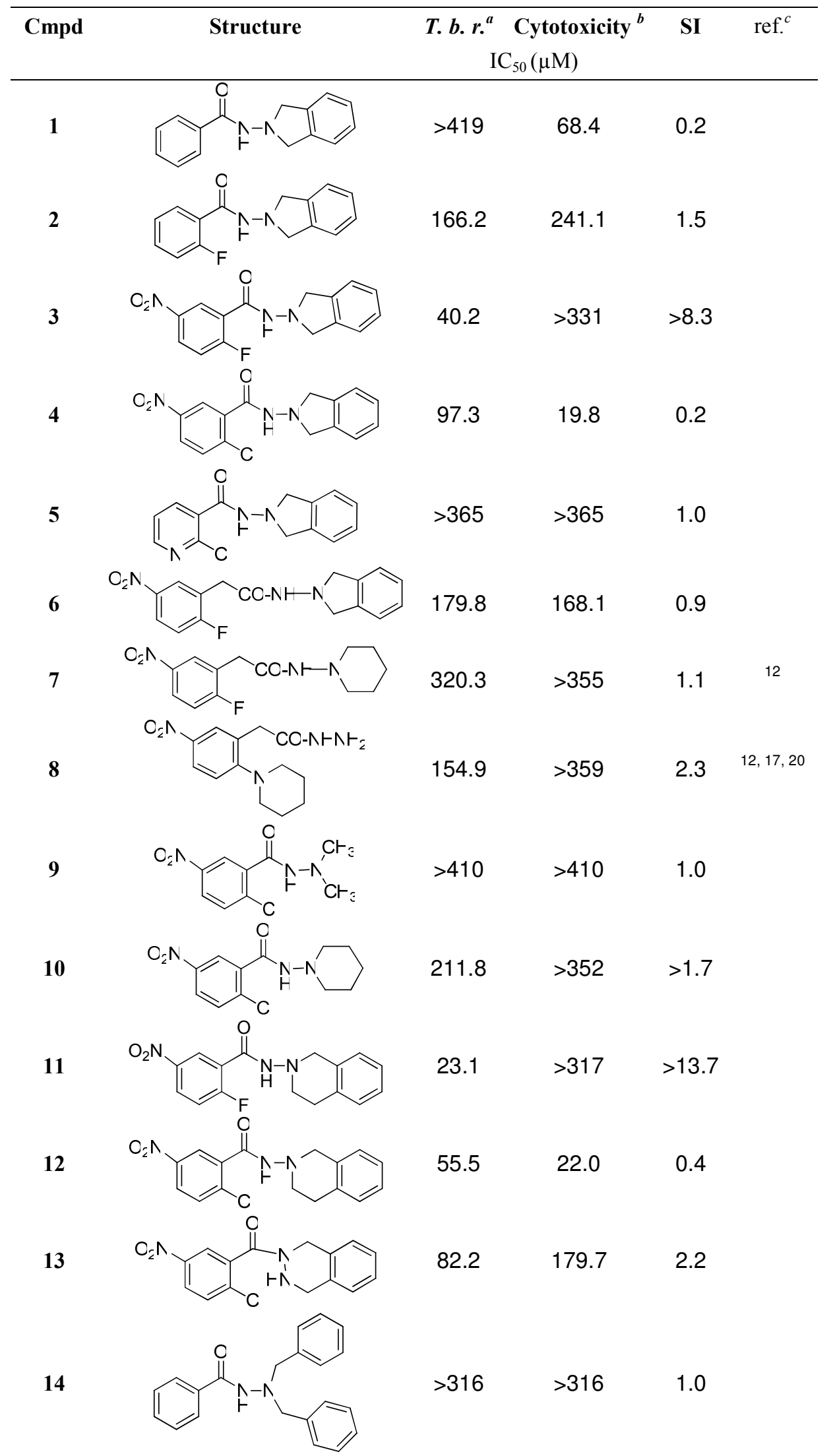

${ }^{a}$ Trypanosoma brucei rhodesiense STIB900. Reference drug: melarsoprol, $\mathrm{IC}_{50}=0.005$ 
$\mu \mathrm{M} ;{ }^{b}$ Rat skeletal myoblast L6-cells. Reference drug: podophyllotoxin, $\mathrm{IC}_{50}=0.019$ $\mu \mathrm{M} ;{ }^{c}$ Bibliographic reference related to other antiparasitic activities of the compound. 
Table 2. In Vitro Activity of Indazol-3-ol (23-39) and Cinnolin-3-ol (40) Derivatives against $T$. brucei rhodesiense.

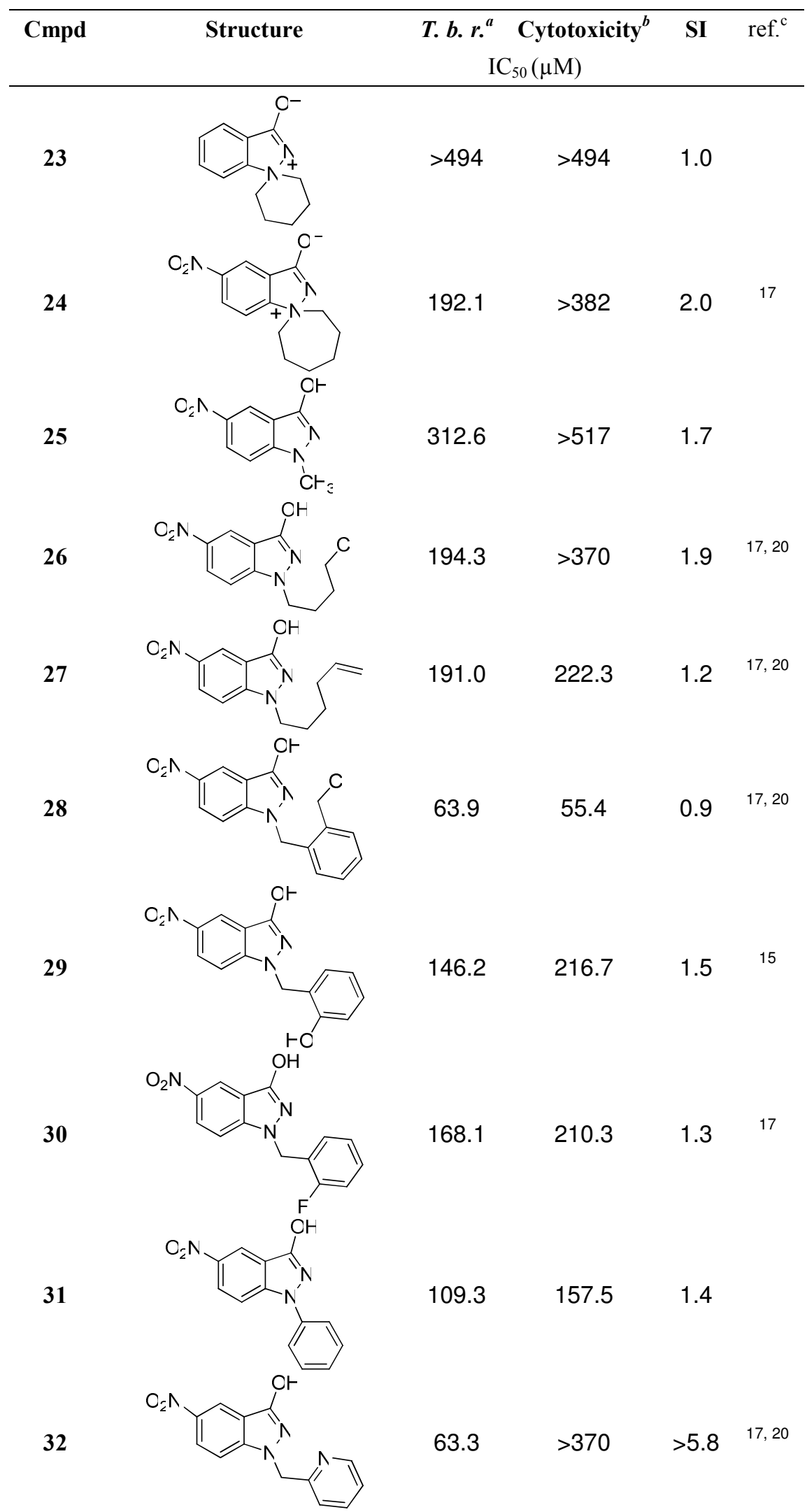

a Trypanosoma brucei rhodesiense STIB900. Reference drug: melarsoprol, $\mathrm{IC}_{50}=0.005$ $\mu \mathrm{M} ;{ }^{b}$ Rat skeletal myoblast L6-cells. Reference drug: podophyllotoxin, $\mathrm{IC}_{50}=0.019$ $\mu \mathrm{M} .{ }^{c}$ Bibliographic reference related to other antiparasitic activities of the compound. 
Table 3. In Vitro Activity of Indazolin-3-one (41-43, 45, 49-56) and Indolin-3-one (44, 47, 48) Derivatives and Related Compounds (46) against $T$. brucei rhodesiense. 


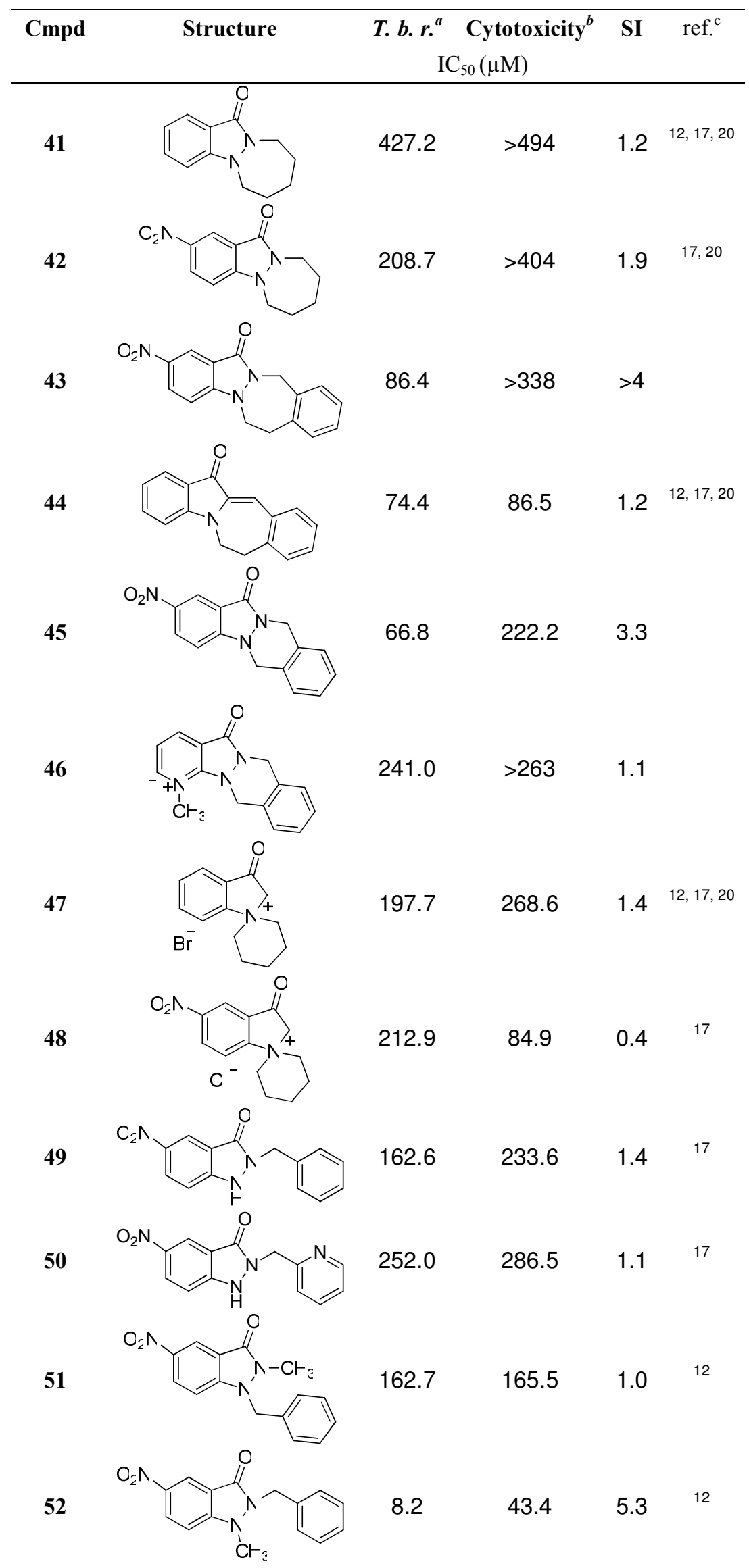

${ }^{a}$ Trypanosoma brucei rhodesiense STIB900. Reference drug: melarsoprol, $\mathrm{IC}_{50}=0.005$ 
$\mu \mathrm{M} ;{ }^{b}$ Rat skeletal myoblast L6-cells. Reference drug: podophyllotoxin, $\mathrm{IC}_{50}=0.019$ $\mu \mathrm{M} .{ }^{c}$ Bibliographic reference related to other antiparasitic activities of the compound. 
Table 4. In Vitro Activity of Quinoxalin-2-one (57-70) and Cinnolin-4-one (71) Derivatives against $T$. brucei rhodesiense. 


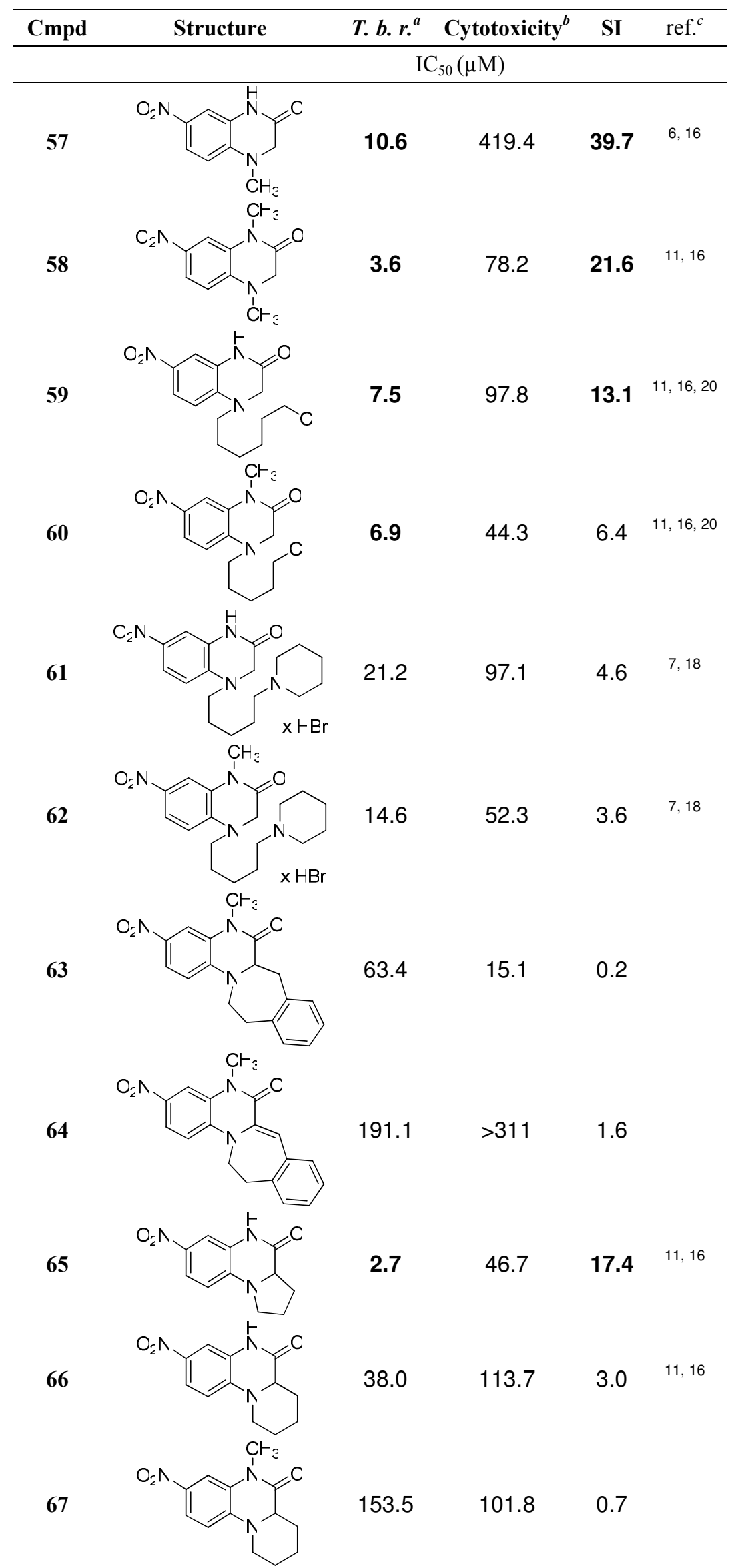

a Trypanosoma brucei rhodesiense STIB900. Reference drug: melarsoprol, $\mathrm{IC}_{50}=0.005$ 
$\mu \mathrm{M} ;{ }^{b}$ Rat skeletal myoblast L6-cells. Reference drug: podophyllotoxin, $\mathrm{IC}_{50}=0.019$ $\mu \mathrm{M} .{ }^{c}$ Bibliographic reference related to other antiparasitic activities of the compound. 
Table 5. In Vitro Activity of Bisindazole Derivatives (72-75) and 1,3-Disubstituted Urea 76 against $T$. brucei rhodesiense.

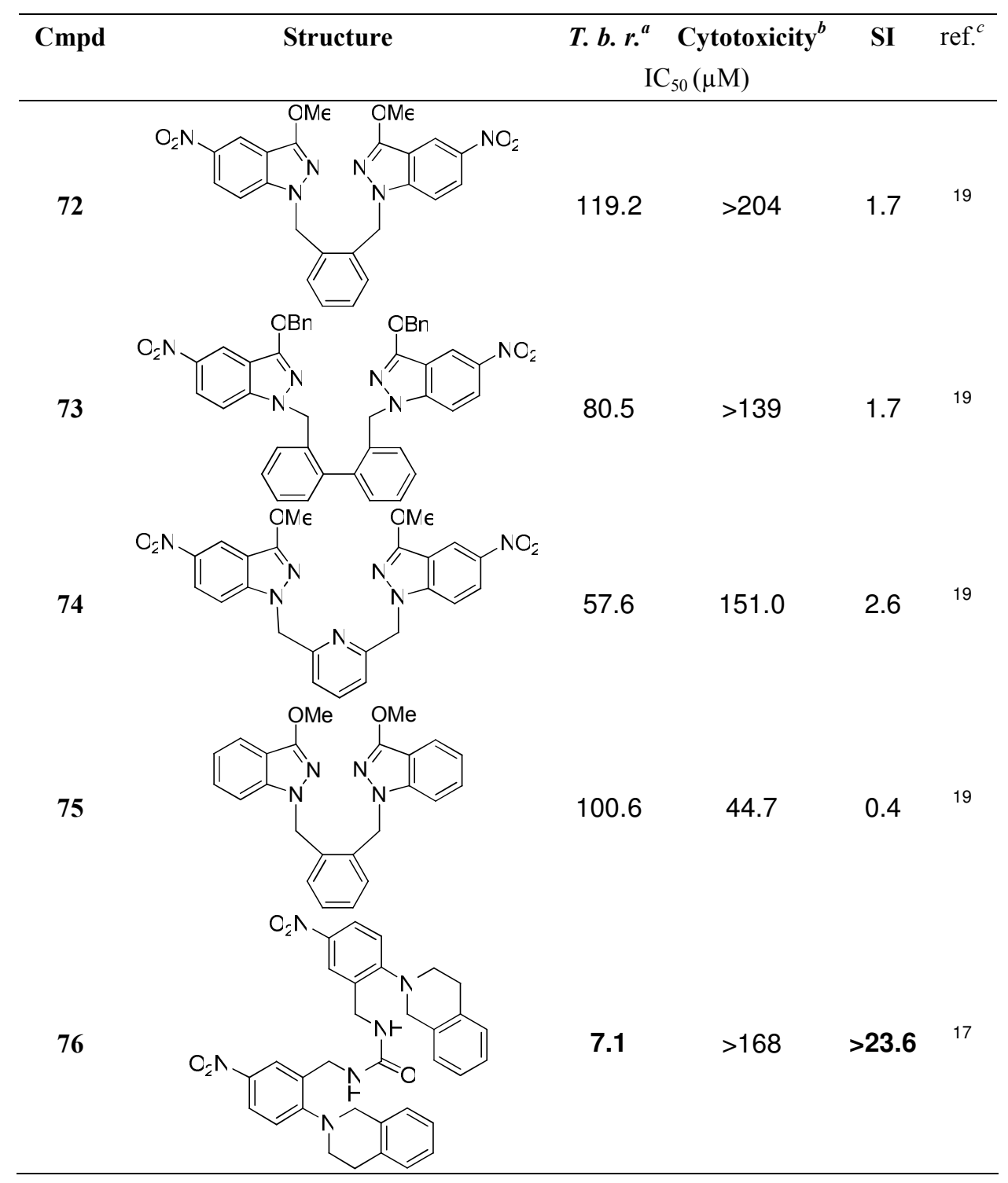

${ }^{a}$ Trypanosoma brucei rhodesiense STIB900. Reference drug: melarsoprol, $\mathrm{IC}_{50}=0.005$ $\mu \mathrm{M} ;{ }^{b}$ Rat skeletal myoblast L6-cells. Reference drug: podophyllotoxin, $\mathrm{IC}_{50}=0.019$ $\mu \mathrm{M} .{ }^{c}$ Bibliographic reference related to other antiparasitic activities of the compound. 